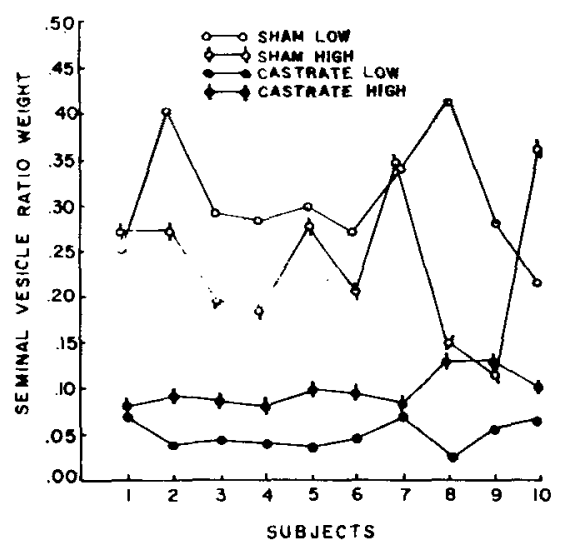

Fig. 1. Profile of seminal vesicle ratio weights across Ss for each subgroup.

$(t=3.91, \mathrm{df}=9, \mathrm{p}<.01)$. Differences in ratio seminal vesicle weights were nonsignificant between sham subgroups $(t=1.72, d f=18, p>.05)$, but these Ss did differ on ratio teste weights $(t=3.34, \mathrm{df}=18, \mathrm{p}<.01)$.

There appears to be sufficient behavioral and physiological data to suggest that castrate subgroups are differentiated by dosage levels and that the high-dosage castrates responded to hormone treatment with more effective dominance behavior against sham opponents during the second home-cage encounter. However, data pertaining to hormone effects on tube dominance and on task-correlated behavior between the tube and the home cage are inconclusive. Still, to claim that we have demonstrated social dominance as a situation-specific phenomenon is to say very little. This claim is suspect becuase it is based on the absence of a task-correlated relationship, a condition which prompts the notion that a change in design or procedure might have manifested the association.

Since it is usually less impressive to demonstrate the absence of a relationship, there is an obligation to seek further justification of the present results. Apart from our immediate evidence, the past history of the dominance tube offers some indirect support for the conclusions drawn. Two experiments by Lindzey and his associates (1966, 1969) revealed that Strain A mice were dominant in tube contests but were less assertive in an open area during spontaneous fighting bouts with Strain DBA mice. The authors suggested that Strain A mice might possess characteristics of "persistence" and "low emotional arousal" which enhanced their success in restrictive tube encounters where scratching and biting are curtailed. Using Sprague-Dawley rats, our assumption

is that castrates adapted quickly to the tube and became conditioned, through early wins or losses, to exercise a repetitive, ritualistic behavior pattern (Wilson, 1968). This behavioral regimen may have been resistant to the effects of testosterone cypionate, since only limited movements are possible in the tube and since opponents were in matched pairs for all contests.

\title{
REFERENCES
}

BAENNINGER, L. Social dominance orders in the rat: "Spontaneous," food, and water competition. Journal of Comparative \& Physiological Psy chology. 1970, 71, 202-209.

LINDZEY, G., MANOSEVITZ, M., WINSTON, H. Social dominance in the mouse. Psychonomic Science, 1966, 5 , 451-452.

\section{The effect of overtraining on}

\section{two extradimensional shifts in rats*}

\section{T. GARY WALLER}

\author{
University of Waterloo, Waterloo, Ont., Canada
}

Rats were either trained to criterion or were given overtraining beyond criterion on an orientation discrimination (left vs right oblique stripes) and were then given an extradimensional shift to a discrimination between two-dimensional shapes (cross vs triangle) or between large and small checkerboard patterns. Position of the positive cue (left or right) was the only variable irrelevant dimension in either phase of the experiment. Overtraining on the orientation discrmination improved performance on both transfer problems.

The effect of overtraining on extradimensional (ED) and intradimensional (ID) shifts has been one of the experimental manipulations frequently used to test preaictions from two-process theories of discrimination learning, such as Sutherland's stimulus-analyzer theory (Sutherland, 1964) or similar theories utilizing an attention construct (e.g., Zeaman \& House, 1963). Recent research (e.g., Shepp \& Turrisi, 1969) has shown, as predicted by the above theories, that overtraining facilitates performance on ID shifts but hinders performance on ED shifts. Typically, studies of ID and ED shifts begin with discrimination problems in which one dimension (Dimension A) is relevant and at least one other dimension (Dimension B) is variable irrelevant (cf. Shepp \& Turrisi, 1966, 1969). During the shift phase, Dimension $B$ is typically made relevant, and Dimension $A$, the dimension relevant during the original acquisition discrimination, is made variable irrelevant. As previously suggested (Waller, 1970), the effect of overtraining on ED shifts has been tested primarily in discrimination

*This research was supported by Grant No. APA-326 from the National Research Council of Canada and by a grant from the University of Waterloo Research Council. Requests for reprints should be addressed to T. Gary Waller, Department of Psychology, University of Waterloo, Waterloo, Ont. Canada. situations which include variable irrelevant cues. In an earlier experiment, Waller (1970) found that overtraining on an orientation discrimination facilitated performance on a subsequent shape discrimination but not on a width discrimination. The purpose of the experiment reported here was (1) to replicate the previously obtained facilitative effect of overtraining on the shift from orientation to shape cues and (2) to extend the previous research by examining the effect of overtraining on an ED shift with transfer cues different from those previously used. Thus, rats were first trained on a stripe-orientation discrimination (left oblique vs right oblique) and were then trained on one of two ED shifts, a cross vs triangle discrimination or a discrimination between large and small checkerboard squares.

\section{SUBJECTS}

The Ss were 32 experimentally naive male albino rats supplied by the Holtzman Co. Ss were reported to be approximately 100 days old on arrival at the laboratory.

\section{APPARATUS}

The apparatus has been described elsewhere (Waller, 1970). Briefly, it was a gray, wooden, Plexiglas-covered discrimination box with start, choice, and goal areas separated by horizontally sliding wooden doors. The start section led into a triangular-shaped choice area, which 
Table 1

Mean Errors to Criterion During Acquisition and Transfer

\begin{tabular}{cccc} 
& Acquisition & and & \multicolumn{2}{c}{ Transfer } \\
\hline \multirow{2}{*}{$\begin{array}{c}\text { Trans- } \\
\text { fer }\end{array}$} & $\begin{array}{c}\text { Amount } \\
\text { of } \\
\text { Task }\end{array}$ & $\begin{array}{c}\text { Experimental } \\
\text { Phase }\end{array}$ \\
\cline { 3 - 4 } Training & $\begin{array}{c}\text { Aequi- } \\
\text { sition }\end{array}$ & $\begin{array}{c}\text { Trans- } \\
\text { fer }\end{array}$ \\
\hline \multirow{2}{*}{ Shape } & Criterion & 33.6 & 21.0 \\
& Overtrained & 31.4 & 15.4 \\
Size & Criterion & 36.2 & 29.1 \\
& Overtrained & 32.8 & 12.0 \\
\hline
\end{tabular}

opened into two adjacent goalboxes. The floor of the goalboxes was $2.5 \mathrm{in}$. below the floor of the choice area. In the rear wall of each goalbox was a 1.5 -in. round hole centered 1.625 in. above the floor of the goalboxes. Food pellets were placed in foodwells located behind swinging doors which covered the holes. To get the reward pellets, $S$ had to put his head through the hole, pushing open the hinged door. The hinged doors in either goalbox could be locked from the outside. Three pairs of stimulus inserts for the rear walls of the goalboxes were cut from Masonite. Two of the pairs were described previously. The first pair was painted with alternating 1 -in. black and white stripes oriented 45 deg to the left or right. The second pair consisted of an equilateral triangle and a symmetrical cross which were white on a black background. The third pair consisted of checkerboard patterns which were either 1.5- or 0.75 -in. alternating black and white squares. The checkerboard patterns covered the entire stimulus insert.

\section{PROCEDURE}

On arrival $S s$ were housed individually and given ad lib food and water for $2-4$ days. Then, to reduce the possibility of drive confounds attributable to differential weight changes in the treatment groups (cf. Clayton, 1965), Ss were placed on a once-daily ration of $10-12 \mathrm{~g}$ of laboratory cubes to maintain a constant $80 \% \quad( \pm 15 \mathrm{~g})$ of terminal ad lib body weight for the remainder of the experiment. Following the ad lib period, each $S$ received $6-8$ days of prehandling during which $S$ was permitted to explore the top of a large gray table for $2 \mathrm{~min}$, was picked up and replaced at least three times by $E$, and was permitted access to five $.045 \mathrm{~g}$ Noyes pellets located in a glass dish in the center of the table.

Following prehandling, each $\mathrm{S}$ received acquisition training on a simultaneous discrimination with orientation of stripes (left slant or right slant) as the relevant cue. For half the Ss, left was positive $\left(\mathrm{S}^{+}\right)$and right was negative ( $\mathrm{S}-$ ); for the other half the conditions were reversed. For each correct response $S$ received five $.045 \mathrm{~g}$ Noyes pellets. $\mathrm{S}$ was never permitted to correct an error, and errors were never rewarded. Ss were confined in the goalbox for 10 sec on nonrewarded trials and until they ate the pellets on rewarded trials. The position of $S^{+}$, right or left, was varied according to randomly selected Gellermann series. A modified correction procedure was used such that, if $S$ made an error, the position of $\mathrm{S}+$ was not changed on the next trial. Ss were run each day until they made a total of 15 correct responses, except that two trials were given on the first day and seven trials were given on the second day. Acquisition training continued for each $S$ until be made 13 correct responses out of any 15 consecutive trials. The within-day intertrial interval was approximately 10 sec.

When $S s$ reached acquisition criterion, they were assigned randomly to one of four treatment groups with the restriction that eight $\mathrm{Ss}$ were assigned to each group. Ss assigned to the criterion training condition began training on a transfer discrimination on the day after they reached acquisition criterion. Ss assigned to the overtraining condition received another 10 days (15 trials/day) of training on the original discrimination and then began training on the transfer discrimination. On the transfer task (an ED shift with no variable irrelevant cues other than position), the relevant cues were either the triangle and the cross or the checkerboard patterns. Equal numbers of Ss were assigned to each set of cues. All procedures were appropriately counterbalanced such that, within each group, for half the Ss trained with left as $S+$ in acquisition, the triangle was $S+$ during transfer, etc. All procedures during transfer were the same as during original acquisition.

Mean errors to criterion during acquisition of the orientation discrimination are shown in Table 1. Acquisition performance was not affected by positive cue during acquisition ( $F<1.0$ ), nor were there any significant acquisition differences among groups subsequently assigned to different training conditions or shift problems. Mean errors during 10 days of overtraining was 37.8 and was not affected by any treatment condition. As shown in Table 1 overtrained animals learned both shift or transfer discriminations faster than animals trained only to criterion. Analysis of variance indicated that overtraining produced significantly superior transfer performance ( $F=4.80$, $\mathrm{df}=1 / 24, \mathrm{p}<.05$ ), that performance on the two discrimination tasks was not different $(F<1.0)$, that the interaction between discrimination task and amount of training was not significant $(F=1.23, \mathrm{df}=1 / 24)$, and that there were no significant main effects or interactions involving positive cue within either discrimination task.

\section{DISCUSSION}

The results reported here confirm previous research (Waller, 1970) in demonstrating that overtraining on an orientation discrimination facilitates performance on an ED shift to a shape discrimination and extend previous research by demonstrating a similar facilitation for a different set of transfer cues (size). Thus, it is clearly established that when there are no variable irrelevant cues, overtraining can facilitate, at least under some circumstances, performance on an ED shift. The results are not compatible with a position which holds that overtraining always strengthens attention to a particular specific stimulus dimension and weakens attention to other specific dimensions. $R$ ather, the results suggest that overtraining strengthens a learning set (Harlow, 1959), a general attentiveness to discriminative cues (Thomas et al, 1970), or, perhaps, an entire branch of hierarchically arranged stimulus analyzers (Sutherland \& Adelman, 1967).

\section{REFERENCES}

C L A Y T O N , K . N N T h e overlearning-reversal-effect: Dependent on a confound with drive? Paper presented at the Southeastern Psychological Association meeting. Atlanta, Georgia, April 1965.

HARLOW, H. F. Learning set and error factor theory. In S. Koch (Ed.), Psychology: A study of a science. Vol. 2. New York: McGraw-Hill, 1959.

SHEPP, B. E., \& TURRISI, F. D. Learning and transfer of mediating responses in discriminative learning. In $N$, R. Ellis (Ed.). International review of research in mental retardation. New York: Academic Press, 1966. Pp. 85-121.

SHEPP, B. E., \& TURRISI, F. D. Effect of overtraining on the acquisition of intradimensional and extradimensional shifts. Journal of Experimental Psychology, 1969, 82, 46-51.

SUTHERLAND, $N$. $S$. The learning of discriminations by animals. Endeavour, $1964,23,148-152$.

SUTHERLAND, N. S., \& ANDELMAN, L. Learning with one and two cues. Psychonomic Science, 1967, 7, 107-108. THOMAS, D. R.. FREEMAN, F. SVINICKI, J. G., BURR, D. E. S., \& LYONS, J. Effects of extradimensional training on stimulus generalization. Joumal of Experimental Psychology Monograph, 1970, 83, No. 1, Part 2.

WALLER, T. G. Facilitation of an extradimensional shift with overtraining in rats. Psychonomic Science, 1970, 20, $172-174$.

ZEAMAN, D., \& HOUSE, B. J. The role of attention in retardate discrimination learning. In N. R. Ellis (Ed.), Handbook of mental deficiency: Psychological theory and research. New York: McGraw-Hill, 1963. Pp. 159-223. 